\title{
A POSTURA FENOMENOLÓGICA ENQUANTO CONTRIBUTO À PESQUISA EM EDUCAÇÃO
}

\author{
Lisiane Costa Claro ${ }^{1}$ \\ Vilmar Alves Pereira ${ }^{2}$
}

\section{Resumo}

Ao identificarmos a fragilidade e o aligeiramento de alguns estudos no campo da educação, quando não articulam os eixos da metodologia com a epistemologia, compreendemos a pertinência da busca pelos fundamentos epistemológicos. Com efeito, objetivamos abordar a fenomenologia enquanto postura agregadora às pesquisas em educação. Para tanto, o texto retoma o surgimento da fenomenologia, enfatizando sua apreensão em Husserl e outros estudiosos, reconhecendo seu legado para o campo dos estudos na área.

Palavras-chave: Postura Fenomenológica. Pesquisa. Educação. Contributo. Husserl.

\section{Resumen}

Mediante la identificación de la debilidad de algunos estudios en el campo de la educación, si no articular la metodología con la epistemología, entendemos la importancia de la búsqueda de los fundamentos epistemológicos. De hecho, nuestro objetivo es hacer frente a la fenomenología como método de agregación de la investigación en educación. Por lo tanto, el texto se hace cargo de la aparición de la fenomenología, haciendo hincapié en su arresto en Husserl y otros estudiosos, reconociendo su legado al campo de los estudios del campo.

Palabras clave: Postura fenomenológica. Investigación. Educación. Contribución. Husserl.

A busca acerca de concepções epistemológicas que contribuem no campo da pesquisa se faz pertinente na medida em que compreendemos que os métodos são influenciados e constituídos a partir das diferentes posturas assumidas na investigação científica. Ou seja, antes mesmo de pensarmos os caminhos metodológicos no bojo da construção do conhecimento, é necessária a compreensão sobre a postura epistemológica que o pesquisador pretende assumir

\footnotetext{
${ }^{1}$ Doutoranda no Programa de Pós-Graduação em Educação Ambiental da Universidade Federal do Rio Grande, PPGEA FURG. E-mail: lisianecostaclaro@hotmail.com.

2 Professor do Instituto de Educação da Universidade Federal do Rio Grande, FURG. E-mail: vilmar1972@hotmail.com.
}

CLARO, Lisiane Costa; PEREIRA, Vilmar Alves. A postura fenomenológica enquanto contributo à pesquisa em educação. Revista Sul-Americana de Filosofia e Educação. Número 25: nov/2015 - abril/2016, p. 97-112. 
frente seu problema/fenômeno de pesquisa. Nesse horizonte, o presente estudo tem como proposta adentrar o universo da Fenomenologia ao retomar as compreensões no que tange sua constituição conceitual, identificando o espaço inaugurado por essa forma de estudo a qual redimensionou as pesquisas em educação. Além disso, buscaremos traçar algumas possibilidades que o campo fenomenológico instigou ao ser recriado.

Desse modo, consideramos esse estudo válido ao pensarmos sobre a mudança que ocorre no que tange aos os estudos na esfera educacional. Apostamos na busca por compreender a dinâmica de novas formas de fazer pesquisa no âmbito da educação, já que tais estudos, por muito tempo, estiveram imersos em um paradigma positivista. A partir de uma vertente diversa, de referência fenomenológica, os estudos brasileiros assumem outros olhares para com seu campo de pesquisa.

Nessa esfera, é necessário questionarmos: O que significa a Fenomenologia? E, não menos pertinente seria ainda indagarmos: Qual sua contribuição no campo do saber? Quais as possibilidades a partir de um estudo fenomenológico? A partir do enfrentamento dessa problemática, utilizamos a metodologia da pesquisa bibliográfica, a qual auxilia na escolha de um processo apropriado para o objetivo traçado, no conhecimento das variáveis e autenticidade da pesquisa (Lima, 2007).

Assim, buscamos constituir este estudo por meio das obras de Husserl, destacando aqui Investigações Lógicas (primeira edição datada de 1900-1901),A Crise das ciências europeias e a fenomenologia transcendental: uma introdução à filosofia fenomenológica (a qual teve publicação parcial em 1936). Além dessa análise clássica, utilizamos em nossa reflexão, obras posteriores ao idealizador desse pensamento e nesse ponto destaca-se a contribuição de MauriceMerleauPonty para a temática. Por fim, chegamos até a possibilidade da perspectiva fenomenológica nas pesquisas qualitativas ao fim do século XX e início do século XXI. Ao partir de novas leituras sobre a fenomenologia, percorrendo o campo da educação, conheceremos as influências dos estudos fenomenológicos atuais de forma a indicar possibilidades a partir dessa abordagem. 


\section{Husserl e a Fenomenologia}

$\mathrm{Na}$ busca pela compreensão dos horizontes percorridos por meio das questões que fomentam essa discussão, é fundamental a procura pelo conhecimento do desenvolvimento desse pensamento o qual se deu na Alemanha. Nesse sentido, voltamos à atenção para Edmund Husserl, um sujeito histórico atuante na virada do século XIX para o XX. Para esse pensador, a Fenomenologia é "um método que sustenta o processo do conhecimento essencialista". Assim, para ele, a Fenomenologia é o "caminho", um método o qual tem por finalidade a constituição da ciência da essência do conhecimento ou doutrina universal das essências.

Cabe destacarmos que o trabalho de Brentano ${ }^{3}$ exerceu forte influência no pensamento de Husserl, quando o mesmo retoma a ideia de "intencionalidade"4 (Capalbo, 1996). A partir desse entendimento, Husserl defendeu uma psicologia descritiva dos elementos que constituem os objetos matemáticos ${ }^{5}$. Esse processo de descrição constituiu uma diversa concepção acerca da subjetividade, já que Husserl passou a adotar o método de análise.

Sobre essa questão, Pereira (2011) ressalta que Descartes foi um sujeito histórico que delineou fortemente a concepção de subjetividade moderna a qual pretendia o encontro das verdades absolutas ao apostar no potencial da razão. Thomé (2008) aborda que a subjetividade em Husserl está arraigada à questão da temporalidade, ao fluxo dos acontecimentos e à transcendência. Portanto, a subjetividade sob a perspectiva husserliana, ganha um sentido diferente do que a razão cartesiana preconizava. Contudo, a busca pela verdade absoluta não se esgota nessa nova compreensão, mas, adquire um sentido alargado quando na

\footnotetext{
${ }^{3}$ Franz Brentano foi, segundo Müller (1995), o responsável pela moderna Psicologia, a qual foi concebida de forma emancipada da Filosofia. Segundo próprio Husserl foi quem iniciou uma discussão que instigaria o pensamento fenomenológico.

${ }^{4}$ Para Brentano, a psicologia humana abarca a ideia de que toda a consideração sobre algo é, na verdade, a consciência de alguma outra coisa. Ou seja, a consciência nunca está em nós mesmos, mas sim em outros espaços. Veremos a seguir a apropriação da ideia de intencionalidade no trabalho com a fenomenologia.

${ }^{5}$ Podemos perceber que além de Brentano, Descartes influenciou o pensamento de Husserl, principalmente na criação do método inaugurado.
} 
perspectiva fenomenológica a razão toma outra dimensão - na qual defende a ideia de que o pensar, a consciência, não é puro.

Assim, de acordo com Lyotard (1999), o filósofo anunciava sua tentativa de constituir a Fenomenologia como uma introdução lógica de contribuição na esfera das chamadas ciências humanas. Tal contribuição ocorreria a partir de seu desejo em definir eideticamente ${ }^{6}$ o objeto, antes mesmo de qualquer experimentação. Portanto, Husserl buscava compreender o significado fundamental do objeto sem, contudo, defini-lo de forma invariável e imutável - o que não significa para esse autor uma definição embasada em incerteza. Pelo contrário,

Como se pode ver e ouvir, a elucidação fenomenológica do conhecimento era uma questão de "vida ou morte" para Husserl. Desesperadamente, ele também buscava a "certeza certa", o fundamento sólido de uma clarificante "crítica da razão". Em outras palavras, Husserl acreditava na edificação de uma ciência transcendental dos fenômenos da consciência enquanto consciência, tomando distância do ceticismo reinante no ambiente intelectual da sua época (GALEFFI, 2000, p.19).

A partir dessas considerações, destacamos que as obras de Husserl contemplam dois momentos distintos, mas que se completam em seu pensamento. Primeiramente, as teses de Husserl parecem apontar para o que ele chama de Fenomenologia Empírica, a qual esteve pautada em uma psicologia descritiva. Logo, tal compreensão é revisada, ainda que não perca seu sentido; Husserl diferencia o método e o realoca como parte de uma Fenomenologia Transcendental (que significa a ciência da essência do conhecimento). Portanto, com esse movimento, a análise em Husserl vai além da descrição das aparências. Dessa forma:

$\mathrm{O}$ interesse transcendental, o interesse da fenomenologia transcendental dirige-se para a consciência, enquanto consciência, vai somente para os fenômenos, fenômenos em

\footnotetext{
${ }^{6}$ Trata-se da compreensão sobre um objeto de análise não como realidade, sobretudo como uma possibilidade de realidade, como um ideal.
} 
duplo sentido: 1) no sentido da aparência (Erscheinung) em que a objetividade aparece; 2 ) por outro lado, no sentido da objetividade (Objektität) tão só considerada, enquanto justamente aparece nas aparências e, claro está, "transcendentalmente", na desconexão de todas as posições empíricas...

Dilucidar estes nexos entre verdadeiro ser e conhecer $e$, deste modo, investigar em geral as correlações entre acto, significação e objeto, é a tarefa da fenomenologia transcendental (ou da filosofia transcendental) (HUSSERL, 1990, p. 13).

Dessa forma, tanto quanto a aparência, que é foco de análise, a própria consciência é compreendida como elemento necessário de investigação para Husserl. Para tanto, o autor compreende a "redução fenomenológica" enquanto possibilidade de acesso ao retorno da consciência. Para o filósofo, esse processo proporcionaria a revelação dos objetos em sua constituição (GALEFFI, 2000).

Para compreendermos um pouco mais sobre esse processo que busca o "não buscar", mas sim abrir-se as manifestações do fenômeno (do mundo vivido, enfim, do objeto ou sujeito de estudo), é importanteatentar para a presença da intencionalidade no pensamento de Husserl. Após, ao conhecermos o sentido da consciência para esse filósofo, se torna possível estudarmos o conceito de redução fenomenológica, a epoché.

\section{Sobre a intencionalidade e a redução fenomenológica - o sentido da epoché}

Tanto a doutrina cartesiana quanto a fenomenologia, buscam a reforma filosófica para obter uma base evidente para as ciências (Husserl, 1992). Assim, ambas as filosofias se aproximam no que tange a intencionalidade de elucidação das ciências. Contudo, segundo Sokolowski (2010), a fenomenologia rompeu com o predicamento egocêntrico, ao dar um "xeque-mate" na doutrina cartesiana" .

Essa superação, por Husserl, da filosofia cartesiana, ocorre a partir do conceito de intencionalidade tecido por esse autor o qual preconiza que Descartes

\footnotetext{
${ }^{7} \mathrm{~A}$ concepção cartesiana tem como um forte elemento a fragmentação dos objetos para que os mesmos sejam estudados. Assim, faz parte do método cartesiano a separação e ordenação por "importância" dos elementos que constituem o objeto a ser pesquisado.
} 
ao afirmar "Penso, logo existo" não abarca a totalidade da ciência, portanto, é uma afirmação inacabada, incompleta; haja vista que em Descartes, a consciência está voltada para ela mesma. Contudo, segundo Husserl, o ato de "pensar" obrigatoriamente se dirige ao que é pensado, ou seja, ao intencionado. Assim, Husserl ressalta que consciência é sempre consciência de alguma coisa (Husserl, 1992).

Ao superar essa questão, o autor aqui enfatizado, introduz sua concepção de intencionalidade de forma a evidenciar o conceito de consciência. Em "Investigações Lógicas", mais especificamente na quinta Investigação lógica, intitulada "Sobre vivências intencionais e seus 'conteúdos'", Husserl aponta que os sentidos de consciência podem ser classificados em três: um sentido está voltado a totalidade do eu empírico - que compreende o fluxo das vivências -, outro como uma compreensão interna - ligada a uma consciência reflexiva interior das vivências $-e$, por último, ressalta o sentido de intencionalidade. Nesse último caso, Husserl aponta que o pensar sobre algo é uma consciência que se origina de outra consciência e assim por diante, ou seja, é sempre a presença intencional de algo.

Sobre esse tema, Husserl, afirma que a fenomenologia "é uma peculiaridade da essência da esfera de vividos em geral, visto que de alguma maneira todos os vividos participam da intencionalidade" (HUSSERL, 2006, p, 47). Além disso, aborda que a intencionalidade caracteriza fundamentalmente a consciência, bem como justifica que designa todo o fluxo das vivências como fluxo de consciência e unidade de "uma únicaconsciência". Portanto, a fenomenologia husserliana se diferencia da esfera em que a consciência é caracterizada segundo as determinações dos objetos ditos "reais". Assim, o que ocorre é a busca por uma análise intencional, que se foca na esfera da consciência transcendental - a qual possui a estrutura fundamental de tais vividos e por isso assume um caráter absoluto (HUSSERL, 2006).

A partir do entendimento acerca do desenvolvimento de estudos sobre a Fenomenologia, tendo como foco o sentido de intencionalidade, consideramos pertinente a inovação que essa dinâmica traz em um contexto característico pelas dicotômicas maneiras de compreender o conhecimento. Husserl abarca um novo 
sentido que se trata da relação indissociável entre o sujeito e o mundo, a consciência e seus objetos.

Husserl, ao vivenciar um contexto no qual a concepção de ciência era cada vez mais enfatizada em meio a mentalidade de uma sociedade com fortes traços modernos, percebe o processo vigente no âmbito do conhecimento - o qual distanciava cada vez mais o conhecimento do mundo prático, visível $e$ palpável.Segundo Luijpen (1973), surge, então, o esforço de retomar à "experiência original" e ao "mundo original" os quais são compreendidos como espaços livres do cientificismo, contrariando a tendência típica de seu período histórico. Por esse processo, conhecemos a epoché de Husserl.

Com isso, o autor aposta nesse esforço de buscar as possibilidades de uma retomada ao sentido original das coisas. Nessa perspectiva, é possível afirmar que Husserl considera a ideia de que o ser humano está imerso em uma compreensão implícita do mundo. Esse pensamento manifesta-se quando o pensador ressalta que o mundo é habitual ao sujeito de maneira em que essa ideia é naturalizada. Assim, coloca: "Eu tenho a consciência de um mundo que se estende sem fim no espaço, que tem e teve um desenvolvimento sem fim no tempo ... descubro [o mundo] por uma intuição imediata, tenho experiência dele" (HUSSERL, 1991, p.37).

Percebemos por meio dessa inferência, a necessidade que Husserl considera ao preconizar uma posição fenomenológica que desloca o foco de evidência das teses cogitativas as quais vinham sendo operadas. Enquanto havia uma inclinação a vivenciar as teses já construídas e seguir tais parâmetros, o autor lança mão de uma nova postura a qual defende ações de reflexão voltadas às operações, buscando compreendê-las como o ser totalizante que são nelas mesmas.

Dessa forma, a epoché ultrapassa a postura natural e provoca o retorno à consciência, "às coisas em si mesmas", como defendia Husserl. Essa mesma consciência é responsável pelo encontro dos objetos constituídos enquanto correlatos da intencionalidade. Assim, lemos:

$\mathrm{Na}$ atitude natural, não cesso de realizar o mundo como ontologicamente válido, esse mundo no qual sou como 
homem ... Minha vida em todos os seus atos é de parte a parte orientada sobre o ente que pertence a tal mundo, todos os meus interesses, nos quais tenho meu ser, são interesses por coisas do mundo, realizando-se em atos que concernem a essas coisas, enquanto elas são o correlato de minha intenção. (HUSSERL, 2008, p.516)

A partir dessa compreensão destacada acima, Husserl busca um processo o qual rompe com os valores desse mundo por meio da redução fenomenológica. Galeffi (2000) expõe que ao final do processo de redução, a consciência despida de outros valores e significações é apresentada em sua originalidade possibilitando maior rigorosidade de estudo em si a partir de uma relação dialética.

Nesse horizonte, a epoché tem como ato o descolamento da atenção do mundo de forma em que desconsidera toda concepção, julgamento e definição fixa acerca do mundo como objeto. Não há espaço para qualquer julgamento a respeito do mundo (Depraz et al. 2006). Assim, a epoché chega ao conhecimento do que existe para além das aparências ao introduzir a subjetividade.

Depraz, et al. (2006), aponta que a redução fenomenológica é um processo realizado pormeio de três momentos, aqui os denominamos de: suspensão, apercepção e devir. A primeira fase correspondente a de suspensão, é caracterizada pela quebra com a atitude naturalizada, isso ocorre por meio da mudança de foco que o sujeito dá ao contexto do mundo prático. Nesta etapa inicial da redução, existe a possibilidade de seu desenvolvimento a partir de algumas formas: quando um acontecimento externo instiga a atitude suspensiva.

A partir dessa postura suspensiva, o sujeito segue para o segundo momento, no qual se converte a atenção do exterior ao interior. A orientação da atividade cognitiva é modificada ao desprender-se do contexto, para que a atenção seja voltada ao mundo interior do objeto. Nesse ponto, da redução fenomenológica, o processo convida o sujeito para além detransformar a relação existencial com o mundo, converter o interesse natural ao objeto na maioria das vezes já préconcebido, rumo a prática que permite o espaço da intenção. No entanto, ressaltamos a presença de um grande desafio nessa etapa do processo, já que a tendência de nossa atitude cognitiva é de voltar-se ao mundo exterior, pois 
estamos em constante contato com as mais variadas informações advindas do mundo e ligadas ao cotidiano.

Por fim, a terceira etapa busca o movimento ir do ato voluntário (explorado no segundo momento da redução) a atitude de escuta, de maneira a acolher a experiência. Essa fase final abre a dinâmica para a possibilidade do devir.Aqui, destacamos o pensamento de Kelker\&Schérer (1982) ao apontarem que a redução fenomenológica desenvolvida por Husserl é a forma exclusiva de alcançar um sentido transcendental na fenomenologia, como desejava, visto que proporciona o encontro com uma nova concepção da experiência do mundo vivido. Aqui, tornase pertinente ressaltar que ao aplicar a redução fenomenológica, chega-se a um estágio no qual o mundo representa um devir, assumindo valores e sentidos originais sem conceitos pré-definidos (Dartigues, 1992).

A redução fenomenológica se constitui num esforço de retornar a atenção ao interior, sem o intuito de busca, mas para compreender aquilo que possa se manifestar.No entanto, Ponty (1999) aponta sobre a tentativa de realizar o processo de redução:

O maior ensinamento da redução é a impossibilidade de uma redução completa. Eis por que Husserl sempre volta a se interrogar sobre a possibilidade da redução. Se fôssemos o espírito absoluto, a redução não seria problemática. Mas porque, ao contrário, nós estamos no mundo, já que mesmo nossas reflexões têm lugar no fluxo temporal que elas procuram captar [...] não existe pensamento que abarque todo o nosso pensamento. (PONTY, 1999, p. 10)

Embora o apontamento do autor citado volte para a impossibilidade da redução completa, isso não significa desprezar as ideias construídas sobre a fenomenologia. Nesse sentido, passamos nossa atenção para as possibilidades $e$ caminhos possíveis a partir do pensamento fenomenológico.

\section{O movimento fenomenológico a partir da percepção}

Após o desenvolvimento sobre a fenomenologia de Husserl, outros autores buscaram relações entre a postura (alguns consideraram enquanto método) 
fenomenológica. A partir desse movimento, destacamos a contribuição do pensamento de Merleau-Ponty quando o mesmo lança olhares para o tema da percepção,

\begin{abstract}
A percepção não é uma ciência do mundo, não é nem mesmo um ato, uma tomada de posição deliberada; ela é o fundo sobre o qual todos os atos se destacam e ela é pressuposta por eles. O mundo não é um objeto do qual possuo comigo a lei de constituição; ele é o meio natural e o campo de todos os meus pensamentos e de todas as minhas percepções explícitas. A verdade não "habita" apenas o "homem interior", ou, antes, não existe homem interior, o homem está no mundo, é no mundo que ele se conhece. Quando volto a mim a partir do dogmatismo do senso comum ou do dogmatismo da ciência, encontro não um foco de verdade intrínseca, mas um sujeito consagrado ao mundo (MERLEAU-PONTY, 1999, p. 6) [Grifos do autor].
\end{abstract}

A inferência acima retoma a ideia de Husserl no que diz respeito a rejeição das dicotomias que colocavam mundo e sujeito em lugares diferentes e isolados ${ }^{8}$. Ainda nessa vertente, Heidgger já havia compilado essa ideia ao destacar o "serno-mundo" como uma expressão composta que "já na sua cunhagem, mostra que pretende referir-se a um fenômeno de unidade" (HEIDEGGER, 1989 p. 90). Dessa forma, o sujeito habita, constrói e se constitui a partir do pano de fundo que é a vida. Ponty (1999) acredita que a partir dessa concepção, a qual envolve o sujeito no mundo a percepção é um tema pertinente a ser considerado. Assim, o autor diz que "[...] evidência é 'a experiência da verdade'. Buscar a essência da percepção é declarar que a percepção é não presumida verdadeira, mas definida por nós como acesso à verdade" (MERLEAU-PONTY, 1999, p. 14).

Com efeito, tal compreensão acerca da "verdade" está diretamente relacionada a percepção do sujeito - que por sua vez, só é um fenômeno devido ao entendimento de que o ser humano vivencia, entrando em contato com sensações e práticas a partir do contexto em que atua. Ora, se o "mundo é não

\footnotetext{
${ }^{8}$ Ainda que para Husserl, o esforço buscar o retorno das coisas a si mesmas exigia a "colocação em parênteses" daquilo que não era considerado pertinente na busca pela redução, como as concepções científicas
} 
aquilo que eu penso, mas aquilo que eu vivo; eu estou aberto ao mundo, comunico-me indubitavelmente com ele, mas não o possuo, ele é inesgotável" (MERLEAU-PONTY, 1999, p. 14) então não há como realizar o isolamento das experiências praticadas por um sujeito. Além disso, podemos afirmar, em concordância com Ponty (1994) que a reflexão acerca de algo só é possível após a percepção do que se manifesta. Poderíamos apontar a ideia deque "vivo, percebo, logo, penso".

Assim, salientamos o quanto a contribuição de Ponty, por meio de sua análise acerca da percepção, bem como a própria postura fenomenológica, se relacionam com as possibilidades no campo da pesquisa.

\section{Possibilidades para o campo da pesquisa}

Ao apresentarmos a fenomenologia, enquanto um campo de estudos que foi muito presente no pensamento de Husserl e Merleau-Ponty compreendemos que tal teoria tomou diferentes espaços no campo do conhecimento e da pesquisa. Apropriações fomentaram novas discussões e abriram diversos horizontes de possibilidades para o trabalho fenomenológico 9 .

Ao compreendermos como Husserl fomentou o início de inúmeras possibilidades acerca de uma forma de se fazer pesquisa a qual compreenda o ser humano independente de seu tempo e espaço, buscamos compreender como a fenomenologia se ocupa das pesquisas mais recentes. Assim,

A fenomenologia é o estudo da experiência humana e dos modos como as coisas se apresentam elas mesmas para nós em e por meio dessa experiência. Tenta restabelecer o sentido da filosofia encontrada em Platão. É, além disso, não só uma revivificação de antiquário, mas algo que confronta as questões levantadas pelo pensamento moderno. Vai além dos antigos e modernos, e se esforça por reativar a vida filosófica em nossas circunstâncias presentes (SOKOLOWSKI, 2010, p. 10).

\footnotetext{
${ }^{9}$ Alguns autores que se destacaram ao desenvolver teses a partir de uma postura fenomenológica são Maurice Merleau-Ponty e Jean-Paul Sartre.
} 
Conforme a citação acima, percebemos outra influência exercida sobre a fenomenologia, inaugurada por Husserl, que é a do pensamento platônico. Aqui lembramos que Platão criou o conceito de "mundo das ideias" o qual correspondia a outro plano ou dimensão que não era sensível, não era material. Para o filósofo, esse mundo a parte existia independente da consciência humana $e$ a verdade, portanto, estava para além das aparências (Chalita, 2004). Não obstante, Husserl busca por meio de um procedimento interrogativo compreender os sentidos dessa aparência sem desprezar a experiência observada.

Por este caminho, Sokolowski (2010) aponta que as noções sobre um "mundo intramental" e um "mundo extramental" são incoerentes, já que a mente e o mundo são correlatos entre si. Além disso, aborda que Fenomenologia defende a mente humana como algo público, a qual age e se expõe publicamente de forma em que ultrapassa seus limites. Esse processo aponta que nada é interno.

Segundo Espósito (1993), a fenomenologia possibilita a compreensão por meio da visão dos sujeitos os quais atuam em seu contexto. Para esse autor, o ser humano é capaz de atribuir significados, constituindo-se enquanto sujeito histórico. Assim, concordamos com a ideia de que "não há homem sem mundo e mundo sem homem" (Bicudo, 2005, p. 24). Da mesma forma, autores como Ricoeur e Ponty afirmam que a fenomenologia possibilita a realização de estudos a partir da linguagem, a qual deve ser fundamentalmente considerada na busca pela compreensão dos contextos e fenômenos a serem investigados.

Ao pensarmos nas possibilidades por meio da Fenomenologia, não queremos aqui preconizar um método a ser seguido de forma rígida e estruturada. De acordo com Masini (1989), quando fazemos referência a uma fenomenologia, não falamos em um método a ser aplicado - muito embora Husserl o compreendesse como método -, mas estamos abordando possibilidade de postura ou atitude fenomenológica. Assim, acreditamos em um exercício de buscar remontar as ações humanas a partir daquilo que se mostra de maneira em que se deve questionar os fundamentos estabelecidos como critério de certeza (ainda que para Husserl, ao final desse processo, seja determinada uma certeza). 
Nesse mesmo horizonte, o qual abarca as aparências das atitudes humanas, Asti-Vera (1980) aponta que seria extremamente errôneo trabalharmos com uma pesquisa a partir das manifestações de indivíduos como se os mesmos - os quais são elementos do estudo - fossem objetos de pesquisa. $O$ autor reivindica a fenomenologia como um campo de possibilidades do pesquisador tratar no campo das ciências sociais com uma objetividade diferente, na qual os seres humanos não são objetos, mas sim sujeitos. Paralelamente, Bruyneet al. (1982), salienta que a fenomenologia constitui um processo epistemológico com o qual as ciências sociais deveriam esclarecer suas questões de pesquisa; visto que vai além da filosofia na perspectiva das ambições estritamente cientificas: "A reflexão fenomenológica guiará o pesquisador quando se tratar de colocar problemas, hipóteses, de destacar conceitos com vistas à elaboração teórica; ela poderá garantira fecundidade sempre renovada da pesquisa"(BRUYNE 1992 p. 79).

Para Trivinõs (1987), a Fenomenologia é o "estudo das essências, e todos os problemas, segundo ela, tornam a definir essências: a essência da percepção, a essência da consciência, por exemplo", bem como se trata de uma postura a qual despreza a essência sob um olhar fixado na existência superficial. Martins e Bicudo (1989), consideram que a fenomenologia é de grande contribuição para o método e para os procedimentos da pesquisa qualitativa. Esses autores salientam que essa postura visa uma compreensão cuidadosa e atenta do fenômeno estudado, deixando de lado generalizações, princípios ou leis, já que o foco da análise situa o especifico, almejando a compreensão do movimento posto em evidência.

Assim, ao entendermos parte das possibilidades oriundas das atitudes que fomentam a elaboração dos métodos de cunho fenomenológico, compreendemos que tais posturas representam uma diferente e contundente maneira de questionar os pressupostos naturalizados socialmente. Tentar deixar de lado estigmas, ideias enraizadas no imaginário, preconceitos e anacronias, é uma tarefa necessária ao pesquisador. Por outro lado, a busca por compreender o meio, levando em conta as manifestações ordinárias, a cultura (in)visível e o próprio imaginário presente em um contexto, é uma ação de grande valia quando pensamos nas pesquisas em educação. 
Considerações sobre a contribuição da conduta fenomenológica nas pesquisas em educação

Após conhecermos parte do legado de Husserl no que concerne ao desenvolvimento da fenomenologia, ao abordarmos suas concepções acerca desse campo, destacando a intencionalidade e a redução para buscar uma postura a qual permita a visibilidade daquilo que se manifesta, consideramos interessante para o nosso estudo alguns breves apontamentos sobre a percepção ressaltada por Ponty.

A partir das contribuições à fenomenologia por parte desse último autor, podemos visualizar o pensamento de que é necessário vivenciar, experimentar o mundo para então percebermos as sensações $e$ as manifestações que emergem desse processo. Assim, o autor aponta que a reflexão acerca de algo é resultado da percepção realizada. Logo, trouxemos os horizontes fenomenológicos no campo da pesquisa. Nesse sentido, as pesquisas qualitativas, em geral, apontam a possibilidade de assumir uma atitude fenomenológica. Por esse prisma, focamos como contribuição desse estudo, a potencialidade da postura fenomenológica nas pesquisas em educação.

Com efeito, consideramos que a pesquisa em educação por meio do cunho fenomenológico gera uma postura que na mesma perspectiva do processo de viver - perceber - refletir, pode ir além dessa dinâmica, visto que permite apráxis (ação reflexão - ação) do sujeito pesquisador. Assim, salientamos que essa postura abre uma imensidão no trabalho junto a educação. De maneira a elucidar, e não fragmentar o campo, algumas possibilidades de assumir a atitude fenomenológica são as pesquisas em Educação Popular, Educação Ambiental e nos Estudos do Cotidiano.

Os campos da educação, especialmente esses três, apresentam a possibilidade de trabalhos com contextos, viabilizando estudos de caso, pesquisas de campo, trabalho com narrativas (e, portanto com a memória e linguagem tema que se relaciona e é discutido na perspectiva fenomenológica), entrevistas abertas e História Oral. O ponto crucial é compreender que a postura epistemológica propicia os contornos a serem tomados pelo percurso da ação que 
é a pesquisa em educação. Ou seja, é por meio do olhar cuidadoso, atento e despido dos óculos com lentes paradigmáticas e fixistas que o movimento da pesquisa em educação de cunho fenomenológico ocorre.

Queremos afirmar com isso, que só essa busca pela compreensão ao adentrar o contexto estudado, sem concepções pré-definidas (e até mesmo rejeitando quaisquer hipóteses - se for possível, haja vista que não é uma tarefa fácil, como a leitura de Husserl poderia quem sabe deixar tal impressão, quiçá realizável) junto às experiências do mundo vivido, percepções, reflexões e ações, pode demonstrar para quais caminhos metodológicos o pesquisador poderá seguir.

Assim, salientamos como uma contribuição significativa da postura fenomenológica no campo das pesquisas em educação, a possibilidade de compreensão. O movimento de buscar o conhecimento a partir do "chão da vida", de forma em que o processo de entendimento sobre um novo ângulo, uma diversa realidade, implica em conhecer o outro e durante esse processo instiga o conhecer a si mesmo.

\section{REFERÊNCIAS}

ASTI-VERA, A. Metodologia da pesquisa científica. Porto Alegre: globo, 1980.

BRUYNE, Paul de; HERMAN, Jacques e SCHOUTHEETE, Marc de. Dinâmica da Pesquisa em Ciências Sociais: Os pólos da prática metodológica. Rio de Janeiro: Francisco Alves, 1982.

BICUDO, M.A.V. Pesquisa Qualitativa: significados e a razão que a sustenta. Revista pesquisa qualitativa. Ano 1, n.1. São Paulo: SE\&PQ, 2005.

CAPALBO C. Fenomenologia e Ciências Humanas. Londrina: ed. UEL., 1996.

CHALITA, Gabriel. Vivendo a filosofia. 2. Ed. São Paulo: Atual editora, 2004.

DARTIGUES, André. O que é a Fenomenologia? 3 ed. Tradução: Maria José J. G. de Almeida. São Paulo, SP: Moraes, 1992.

DEPRAZ, Natalie; VARELA, Francisco J.;VERMERSCH, Pierre. (2006). A Redução à Prova da Experiência. Tradução de André Eirado e Virgínia Kastrup. Arquivos Brasileiros de Psicologia, 58(1). Acesso em 14 de junho de 2011, disponível em: http://redalyc.uaemex.mx/src/inicio/ArtPdfRed.jsp?iCve $=229017446008$

ESPOSITO, V.H.C. Pesquisa Qualitativa: Modalidade FenomenológicoHermenêutica. Relato de uma Pesquisa. In: BICUDO, M.A.V.; ESPOSITO, V.H.C. 
(org.) A pesquisa qualitativa em educação: um enfoque fenomenológico. Piracicaba: Editora UNIMEP, 1994.

GALEFFI, Augusto Dantes. (2000). O que é isto - A Fenomenologia de Husserl? Ideação, Feira de Santana, n. 5. Acesso em 03 de abril de 2011, disponível em http://www.uefs.br/nef/dante5.pdf

HUSSERL, Edmund. A Idéia da Fenomenologia. Tradução: Artur Morão. Lisboa: Edições 70, 1990.

KELKEL, Arion L.; SCHÉRER, René.(1982). Husserl. Tradução: Joaquim João Coelho Rosa. Lisboa: Edições 70.

HUSSERL, Edmund. A Crise das ciências europeias e a fenomenologia transcendental: uma introdução à filosofia fenomenológica. Tradução de Diogo Falcão Ferrer. Lisboa: Centro de Filosofia da Universidade de Lisboa, 2008.

HUSSERL, Edmund. Conferências de Paris. Tradução de Artur Morão, António Fidalgo. Lisboa: Ed. 70, 1992.

HUSSERL, Edmund. Idéias para uma fenomenologia pura e para uma filosofia fenomenológica: introdução geral à fenomenologia pura. Tradução de Márcio Suzuki. Aparecida: Idéias \& Letras, 2006

LUIJPEN, W. (1973). Introdução à Fenomenologia Existencial. Tradução: Carlos Lopes de Mattos. São Paulo, SP: Editora Pedagógica e Universitária Ltda.

MASINI, Elsie F.S. O enfoque fenomenológico de Pesquisa em Educação. Cortez, 1989.

MERLEAU-PONTY, Maurice. Fenomenologia da percepção. 2- ed. - São Paulo. Martins Fontes, 1999.

MÜLLER, B. Introduction. In F. Brentano, Descriptive psychology.London: Routledge, 1995.

PEREIRA, Vilmar. Descartes e Rousseau: Leituras antagônicas de infância $e$ subjetividade. In.: POIÉSES- Revista do Programa de Pós-Graduação em Educação. Universidade do Sul de Santa Catarina, jan/jun 2011.

THOMÉ, Scheila. Subjetividade e tempo na fenomenologia husserliana. Trabalho de Dissertação. Curitiba, 2008.

LYOTARD, J. F. A Fenomenologia. Lisboa. Edições 70, 1999.

SOKOLOWSKI, Robert. Introdução à Fenomenologia.. São Paulo. Ed. Loyola, 2011. 